\title{
Considerations when combining data from multiple nutrition experiments to estimate genetic parameters for feed efficiency
}

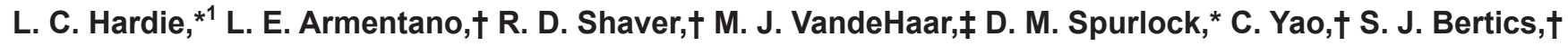 \\ F. E. Contreras-Govea, $†$ and K. A. Weigel† \\ *Department of Animal Sciences, lowa State University, Ames 50011 \\ †Department of Dairy Science, University of Wisconsin, Madison 53706 \\ ‡Department of Animal Sciences, Michigan State University, East Lansing 48824
}

\section{ABSTRACT}

Prior to genomic selection on a trait, a reference population needs to be established to link marker genotypes with phenotypes. For costly and difficult-tomeasure traits, international collaboration and sharing of data between disciplines may be necessary. Our aim was to characterize the combining of data from nutrition studies carried out under similar climate and management conditions to estimate genetic parameters for feed efficiency. Furthermore, we postulated that data from the experimental cohorts within these studies can be used to estimate the net energy of lactation $\left(\mathrm{NE}_{\mathrm{L}}\right)$ densities of diets, which can provide estimates of energy intakes for use in the calculation of the feed efficiency metric, residual feed intake (RFI), and potentially reduce the effect of variation in energy density of diets. Individual feed intakes and corresponding production and body measurements were obtained from 13 Midwestern nutrition experiments. Two measures of RFI were considered, $\mathrm{RFI}_{\mathrm{Mcal}}$ and $\mathrm{RFI}_{\mathrm{kg}}$, which involved the regression of $\mathrm{NE}_{\mathrm{L}}$ intake (Mcal/d) or dry matter intake (DMI; $\mathrm{kg} / \mathrm{d}$ ) on 3 expenditures: milk energy, energy gained or lost in body weight change, and energy for maintenance. In total, 677 records from 600 lactating cows between 50 and $275 \mathrm{~d}$ in milk were used. Cows were divided into 46 cohorts based on dietary or nondietary treatments as dictated by the nutrition experiments. The realized $\mathrm{NE}_{\mathrm{L}}$ densities of the diets (Mcal/ $\mathrm{kg}$ of DMI) were estimated for each cohort by totaling the average daily energy used in the 3 expenditures for cohort members and dividing by the cohort's total average daily DMI. The $\mathrm{NE}_{\mathrm{L}}$ intake for each cow was then calculated by multiplying her DMI by her cohort's realized energy density. Mean energy density was 1.58 $\mathrm{Mcal} / \mathrm{kg}$. Heritability estimates for $\mathrm{RFI}_{\mathrm{kg}}$, and $\mathrm{RFI}_{\mathrm{Mcal}}$ in a single-trait animal model did not differ at 0.04

Received July 7, 2014.

Accepted December 18, 2014.

${ }^{1}$ Corresponding author: lhardie@iastate.edu for both measures. Information about realized energy density could be useful in standardizing intake data from different climate conditions or management systems, as well as investigating potential genotype by diet interactions.

Key words: feed efficiency, residual feed intake, energy density, genetic selection

\section{INTRODUCTION}

Feed costs are a major expense for US dairy producers, accounting for $56 \%$ of total costs of producing milk and offering potential for increased feed efficiency to improve the economic position of dairy producers (USDA-NASS, 2013). Additionally, a general rise in concern over its carbon footprint has led the US dairy industry to establish a goal of reducing greenhouse gas emissions by $25 \%$ by 2020 (Connor et al., 2012). Feed efficiency is a major source of variation in the carbon footprint associated with milk production; thus, its improvement could offer substantial reductions in greenhouse gas emissions (Connor et al., 2012).

An increasingly common measure of feed efficiency is residual feed intake (RFI), which is defined as the difference between the actual intake and predicted intake after adjusting for level of production, usually through linear regression. A cow with negative RFI is expected to convert feed to energy more efficiently than a cow with neutral or positive RFI. Residual feed intake was first used as a measure of feed efficiency in cattle by Koch et al. (1963) when they regressed DMI on live weight and daily gain in growing beef cattle. In lactating dairy cattle, intake is typically regressed on milk yield, BW, and change in BW or body condition (Buttazzoni and Mao, 1989; Van Arendonk et al., 1991; Veerkamp et al., 1995; Vallimont et al., 2011).

Statistically, the phenotype for RFI is a residual term that includes the variation associated with feed efficiency, but it also includes errors associated with measurements of its component traits (Koch et al., 1963). If the coefficients used to compute RFI are gen- 
erated through least squares means, it is phenotypically independent from its component traits (Koch et al., 1963; Korver, 1988; Korver et al., 1991; Arthur et al., 2001b). However, an adverse effect on the component traits could occur if genetic correlations are not zero (Kennedy et al., 1993). Furthermore, the presence of $\mathrm{BW}$ in the regression for RFI forgives large cows for the extra feed required to satisfy their higher maintenance costs, and their increased salvage values may not be large enough to compensate the added maintenance costs incurred over their lifetimes.

The expenses and difficulties associated with measuring individual animal feed intakes, which are necessary for calculating measures of feed efficiency, are considerable. Genomic selection offers a relatively inexpensive solution, as compared with conventional progeny testing. However, before genomic selection for any trait, a reference population of animals with phenotypes and genotypes must be established so that the genetic variation associated with a particular polymorphism can be assigned (Hayes et al., 2009). Subsequent generations can then be genotyped and selected based on genomic EBV derived solely from markers in the absence of phenotypic data (Meuwissen et al., 2001).

The key to effective genomic selection for a trait is the establishment of a reference population that is large enough to provide accurate estimates of SNP effects. Hayes et al. (2009) demonstrated that if a trait is moderately heritable, 0.35 for example, a reference population of approximately 8,000 animals is needed to predict genomic breeding values with an accuracy of $80 \%$. Furthermore, continued collection of phenotypes over time is necessary because linkage disequilibrium dissipates over generations. These requirements are difficult to meet when recording of phenotypes is very expensive, such as for RFI, so collaboration across disciplines, experimental sites, and countries is important (Banos et al., 2012). de Haas et al. (2012) demonstrated that the accuracy of genomic prediction for DMI can increase by up to $5.5 \%$ when using a trivariate model that incorporated feed intake data from 3 countries, as compared with univariate models implemented within each country.

Nutrition studies carried out in experimental herds represent a potential source of individual feed intake data from lactating dairy cattle. These studies are characterized by meticulous record keeping, and diets generally meet or exceed the animals' nutritional requirements, but variation in feedstuffs tested and levels of nutrients provided could add variation to RFI measurements. One way to combat this is with the Net Energy System (NRC, 2001). Fan et al. (1995) cites the convenience of calculating dietary requirements in terms of net energy, such that animal requirements are independent of diet, and feed requirements for maintenance are estimated separately from the requirements for productive functions. The $\mathrm{NE}_{\mathrm{L}}$ of a diet refers to the energy produced in milk, expended as maintenance, and stored in or mobilized from body tissues after consumption of that diet. The calculation of $\mathrm{NE}_{\mathrm{L}}$ typically uses nutrient analyses of TMR samples, but, if data are sourced from many different collaborators and experiments, this information may be difficult to acquire. Therefore, we propose to calculate $\mathrm{NE}_{\mathrm{L}}$ within each cohort based on total feed consumed and total energy expended. The objective of our study was to consider the use of phenotypic data from nutrition studies for genetic analyses of feed efficiency in lactating cows, more specifically: (1) evaluate estimates of genetic parameters for RFI and its component traits obtained from small cohorts and a wide array of diets used in nutrition studies, and (2) propose a method for estimating $\mathrm{NE}_{\mathrm{L}}$ intake within each experimental cohort for the purpose of computing RFI.

\section{MATERIALS AND METHODS}

\section{Data Collection}

Data were pooled from 13 nutrition studies carried out between 2007 and 2012 in 3 Midwestern research herds, as summarized in Table 1 and depicted graphically in Figure 1. Eight studies were from the University of Wisconsin (UW)-Madison Integrated Dairy Facilities, with 6 at the Emmons Blaine Dairy Cattle Research Center (Arlington, WI) and 2 at the Dairy Cattle Instructional Center (Madison, WI). Four were from the USDA-Agricultural Research Service (ARS) Dairy Forage Research Center (Prairie du Sac, WI), and one was from the Cargill Innovation Center (Elk River, MN). All data were collected according to approved animal care and use protocols at the respective institutions. Individual intakes for the 6 studies at the Emmons Blaine Dairy Cattle Research Center were recorded via electronic gates (RIC system, Insentec, Marknesse, The Netherlands); see Chapinal et al. (2007) for a detailed description of the system. In the 2 remaining UW-Madison studies, as well as the studies carried out at the USDA-ARS Dairy Forage Research Center and the Cargill Innovation Center, daily intakes were recorded manually via weigh-backs in a tiestall setting. Eleven of the trials started on the same date for all cows, and for those trials cohorts were assigned based on dietary or nondietary treatments. In the 2 remaining trials, start dates were based on calving dates, and cohorts were assigned initially based on dietary or nondietary treatments followed by additional stratification based on time, such that the cows in each cohort 
Table 1. Information from the 13 nutrition experiments that contributed intake data to this study

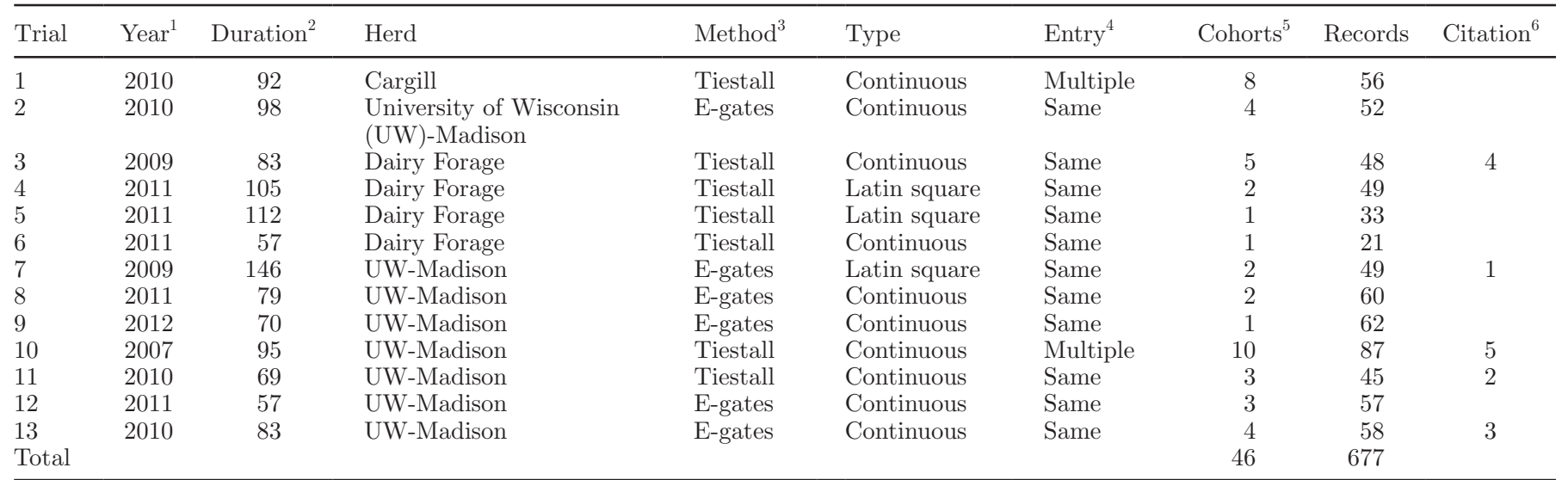

${ }^{1}$ The year of the start of the trial.

${ }^{2}$ The median length (in days) of records.

${ }^{3}$ Daily individual feed intake for cows housed in tiestalls was calculated by subtracting the daily refusals from the feed offered. Individual feed intake for cows housed in freestalls was recorded via electronic gates (E-gates).

${ }^{4}$ Entries coded as "same" denote that all cows started treatments on approximately the same calendar date. Entries coded as "multiple" denote that the start date of the record of a cow was determined by its DIM.

${ }^{5}$ For most trials, the number of cohorts reflects the number of diet or nondietary treatments within each trial. Trials with multiple entries had each treatment split into 2 cohorts based on entry date so that cows within each cohort experienced similar environmental conditions. All cows within the same cohort in a Latin square study received the same diets, though they may have been in different orders.

${ }^{6}$ 1: He et al., 2012; 2: Ferraretto et al., 2011; 3: Ferraretto et al., 2012; 4: Chen et al., 2011; 5: Akins et al., 2013.

experienced similar environmental and management conditions. Ten of the studies were continuous, with cows receiving the same diet for the duration of the study; in some cases this followed a covariate period that allowed cows to adapt to a common diet before initiation of specific treatments. The remaining 3 studies followed a Latin square design in which all cows in the same cohort were subjected to every dietary treatment for the same duration of time, but with treatments applied in different orders.

In total, 677 records from 600 Holstein or crossbred ( $\geq 87.5 \%$ Holstein and $\leq 12.5 \%$ Jersey) cows were used. The observation period for each nutrition study was cropped such that all cows had a BW $(\mathrm{kg})$ measurement before or on the first day of the recording period. Therefore, starting BW was measured between $\mathrm{d}-14$ and 0 relative to the first feed intake measurement. Ending BW was recorded on the last day of the observation period for all cows. The frequency of BW measurements during the observation period varied from a single observation at the beginning and end of the observation period to weekly measurements throughout the observation period, depending on the experiment. As a result, linear regression was applied to BW measurements of individual cows, and the slope of the fitted line represented the cow's BW change $(\mathbf{B W C} ; \mathrm{kg} / \mathrm{d}$ ). Daily fitted values for BW were calculated, raised to the 0.75 power, and averaged to generate a single metabolic BW phenotype for each animal.
Body condition score was recorded on a 1- to 5-scale (Edmonson et al., 1989) at least once during 8 of the 13 trials; if multiple scores existed they were averaged across the observation period. Records without BCS measurements were assigned a score of 3.0, which was the average $(\mathrm{SD}=0.42)$ for studies that provide BCS data. These BCS were used to calculate the energy gained or lost as body weight change (BWCE), as described below.

Because our study focused primarily on feed efficiency during or after peak lactation, and to avoid variation due to management and environmental factors in the early postpartum period, milk and intake data recorded before 50 DIM, if any, were discarded. Seven studies provided milk weights for every milking, 3 provided daily averages, 2 (Latin square) studies provided milk weights during the final week of each treatment period, and 1 study provided weekly averages. Samples for fat, protein, and lactose percentage were taken at various intervals, typically weekly except for Latin square studies, in which milk components were analyzed during the final week of each treatment period. Similarly, feed intakes were typically recorded on a daily basis, but in Latin square studies feed intake measurements were limited to the final week of each treatment period. In total, 246 lactation records were available from primiparous cows and 431 lactation records were available from multiparous cows. 
A

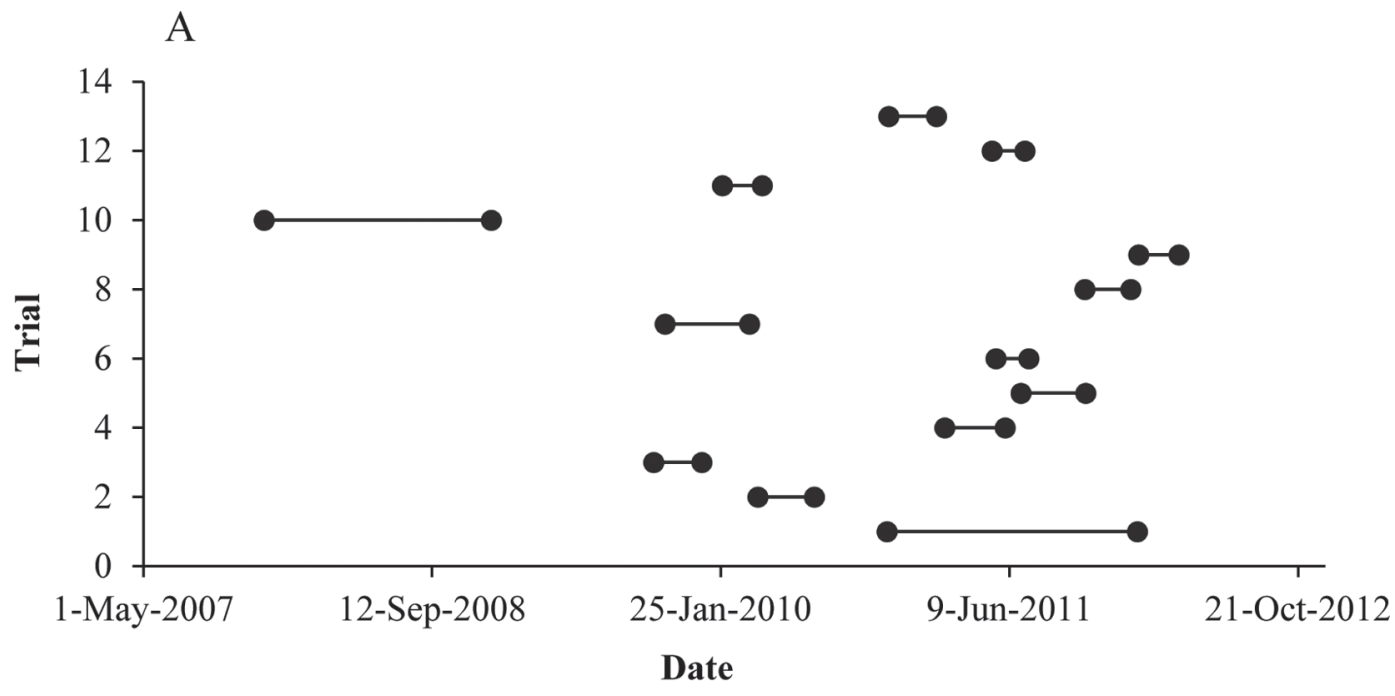

$\mathrm{B}$

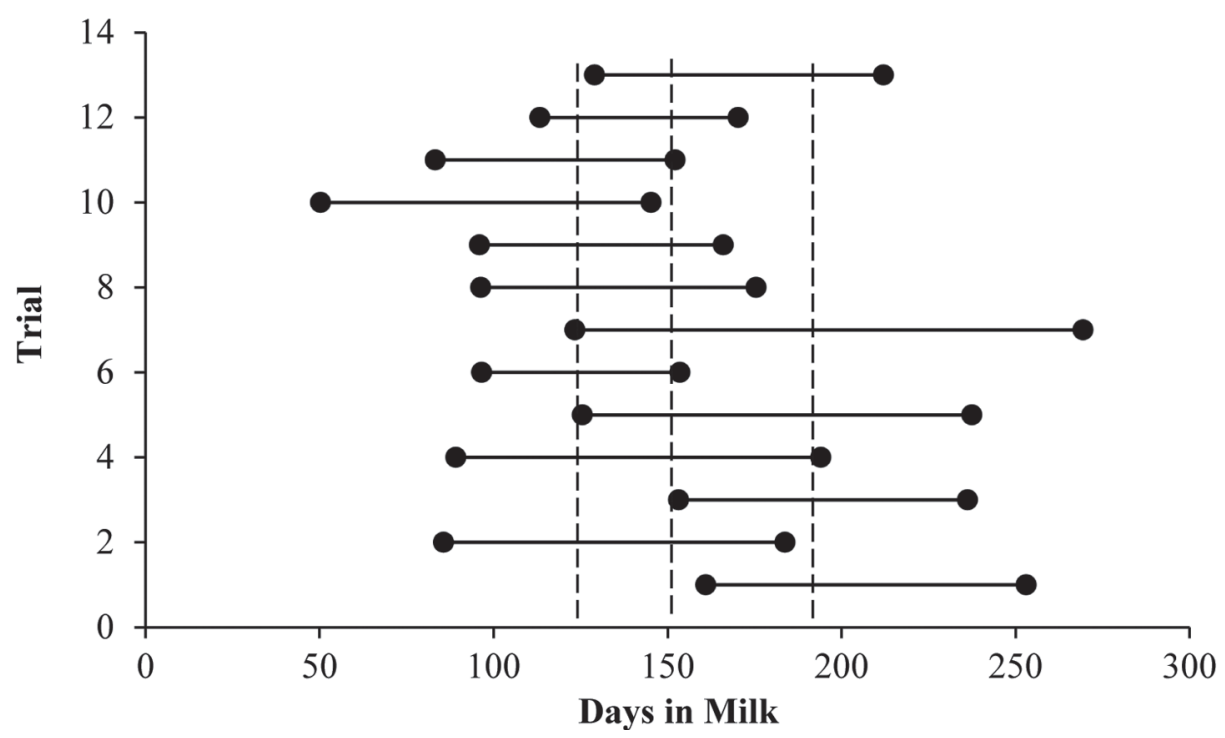

Figure 1. The duration of each nutrition study displayed as (A) the average DIM at the start and end of each study and (B) the calendar dates. The dashed lines represent the average DIM across all studies at the $25 \mathrm{th}, 50 \mathrm{th}$, and $75 \mathrm{th}$ percentile.

\section{Energy Conversions}

Energy requirements for each the following expenditures were converted to the Net Energy System as follows (NRC, 2001). Energy expended in milk (MILKE) was calculated as

$$
\begin{gathered}
\text { MILKE }(\mathrm{Mcal} / \mathrm{d})=0.00929 \times \mathrm{g} \text { of fat } / \mathrm{d}+0.00563 \\
\times \mathrm{g} \text { of true protein } / \mathrm{d}+0.00395 \times \mathrm{g} \text { of lactose } / \mathrm{d}
\end{gathered}
$$

Energy gained or expended in change in BW was calculated as

$$
\begin{aligned}
& \text { BWCE }(\mathrm{Mcal} / \mathrm{d})=\text { BWC }(\mathrm{kg} / \mathrm{d}) \\
& \times(2.88+1.026 \times \mathrm{BCS}) \times 0.85
\end{aligned}
$$

for an increase in BW, whereas, for a decrease in BW, it was calculated as

$$
\begin{aligned}
& \text { BWCE }(\mathrm{Mcal} / \mathrm{d})=\text { BWC }(\mathrm{kg} / \mathrm{d}) \\
& \times(2.88+1.026 \times \mathrm{BCS}) \times 0.82 .
\end{aligned}
$$

Energy expended for maintenance (MAINE) was calculated as 
$\operatorname{MAINE}(\mathrm{Mcal} / \mathrm{d})=0.08 \times$ metabolic BW.

The $\mathrm{NE}_{\mathrm{L}}$ intake $\left(\mathbf{N E}_{\mathbf{L}} \mathbf{i n}\right)$ for each animal was estimated by multiplying the average daily DMI $(\mathrm{kg})$ for each record by the $\mathrm{NE}_{\mathrm{L}}$ density $(\mathrm{Mcal} / \mathrm{kg}$ ) of the diet provided to the animal's cohort. Expressing intake in $\mathrm{NE}_{\mathrm{L}}$, rather than DMI, accounted for dietary influences on the slope of the regression of intake on MILKE, MAINE, and BWCE. Otherwise, for example, highproducing cows on a low-energy diet would need to eat increasingly larger quantities of feed to meet their energy demands, as compared with high-producing cows on a high-energy diet. To obtain the energy densities for specific diets, the energy expenditures for MILKE, BWCE, and MAINE were summed over the observation period within each cohort and divided by the total DMI of all cows in the cohort. Because the cows were housed in freestalls or tiestalls, energy expenditures for physical activity were not considered. In addition, due to an average midpoint DIM of $150 \mathrm{~d}$ for intake measurements the energy required to maintain pregnancy was deemed as negligible and was not considered in the analyses.

\section{Genetic Analysis}

All genetic analyses were performed using ASReml (Gilmour et al., 2008). Ultimately, after performing the calculations described above, there were 677 phenotypic records, each consisting of 1 value for DMI, MILKE, BWCE, MAINE, and associated effects. Five generation pedigrees, leading to a pedigree file with 3,689 animals, were obtained from the USDA-ARS Animal Genomics and Improvement Laboratory (Beltsville, MD). Variance components for measures of RFI were estimated using alternative versions of the following models, where $\mathrm{RFI}_{\mathrm{kg}}$ reflects RFI measured as DMI $(\mathrm{kg} / \mathrm{d})$ and $\mathrm{RFI}_{\text {Mcal }}$ reflects RFI measured as $\mathrm{NE}_{\mathrm{L}}$ intake (Mcal/d):

$$
\begin{gathered}
y_{\mathrm{ijkl}}=\text { Cohort }_{\mathrm{i}}+\mathrm{AP}_{\mathrm{j}}+\mathrm{a}_{\mathrm{k}}+\mathrm{pe}_{\mathrm{k}}+\beta_{1} \mathrm{DIM}_{\mathrm{ijkl}} \\
+\beta_{2} \mathrm{MILKE}_{\mathrm{ijkl}}+\beta_{3} \mathrm{BWCE}_{\mathrm{ijkl}}+\beta_{4} \mathrm{MAINE}_{\mathrm{ijkl}}+\mathrm{e}_{\mathrm{ijkl}},
\end{gathered}
$$

where $\mathrm{y}_{\mathrm{ijkl}}=$ feed intake measured as DMI $(\mathrm{kg} / \mathrm{d})$ for $\mathrm{RFI}_{\mathrm{kg}}$ or as $\mathrm{NE}_{\mathrm{L}}$ in $(\mathrm{Mcal} / \mathrm{d})$ for $\mathrm{RFI}_{\mathrm{Mcal}} ;$ Cohort $_{\mathrm{i}}=$ fixed effect of cohort $\mathrm{i} ; \mathrm{AP}_{\mathrm{j}}=$ fixed effect of parity and age at calving class $\mathrm{j} ; \mathrm{a}_{\mathrm{k}}=$ random animal effect with $\mathrm{a} \sim \mathrm{N}\left(0, \mathbf{A} \sigma_{a}^{2}\right)$, where $\mathbf{A}$ is the additive genetic relationship and $\sigma_{a}^{2}$ is the genetic variance; $\mathrm{pe}_{\mathrm{k}}=$ random permanent environmental effect for animal $k$ with pe $\sim \mathrm{N}\left(0, \mathbf{I} \sigma_{p e}^{2}\right)$, where $\mathbf{I}$ is the identity matrix and $\sigma_{p e}^{2}$ is permanent environmental variance; DIM $_{\mathrm{ijkl}}=$ days in milk at the midpoint of the observation period with coefficient $\beta_{1}$; MILKE $_{\mathrm{ijkl}}=$ partial regression on energy expended in milk (Mcal/d) with coefficient $\beta_{2} ;$ BWCE $_{\mathrm{i}-}$ ${ }_{\mathrm{jkl}}=$ partial regression on energy expended for body weight change (Mcal/d) with coefficient $\beta_{3} ; \mathrm{MAINE}_{\mathrm{ijkl}}$ $=$ partial regression on energy expended for maintenance $(\mathrm{Mcal} / \mathrm{d})$ with coefficient $\beta_{4}$; and $\mathrm{e}_{\mathrm{ijkl}}=$ random error. A fixed effect of year-season was considered but was not included in the analyses because the effect of short-term environmental and management factors was captured by the cohort effect. Univariate analyses were carried out to obtain estimates of the additive, permanent environmental, and residual variances for RFI and its component traits, whereas bivariate analyses were carried out to obtain estimates of genetic correlations between the components of RFI. The bivariate analyses used a similar model, maintaining cohort and parity as class effects, DIM as a covariate, and animal, permanent environment, and error as random terms. For each random term, covariances between the 2 traits were permitted.

\section{RESULTS AND DISCUSSION}

\section{Phenotypic Means}

Means and standard deviations for phenotypes considered in our study are provided in Table 2. On average, primiparous cows gained $0.1 \mathrm{~kg}$ more weight per day than multiparous cows. This is most likely due to the fact that BW change includes growth, which is minimal in multiparous cows. Body weights of primiparous cows $(595 \mathrm{~kg})$ were similar to those observed in Vallimont et al. (2010) and Spurlock et al. (2012) at 150 DIM, the average midpoint DIM in our study. However, multiparous cows in the current study had heavier mean BW $(691 \mathrm{~kg})$ than those in Spurlock et al. (2012), but were similar to third and later parity cows in Vallimont et al. (2010). Average MILKE was greater in Spurlock et al. (2012; 26.2 and $34.3 \mathrm{Mcal} / \mathrm{d}$ for primiparous and multiparous cows, respectively) than in our study (24.3 and $30.5 \mathrm{Mcal} / \mathrm{d}$ for primiparous and multiparous cows, respectively). However, Spurlock et al. (2012) included records from calving to 150 DIM, whereas the present study had an average midpoint of 150 DIM. Realized $\mathrm{NE}_{\mathrm{L}}$ densities of the diets averaged $1.58 \mathrm{Mcal} / \mathrm{kg}$, very close to the recommendation of $1.55 \mathrm{Mcal} / \mathrm{kg}$ for a mature $(680 \mathrm{~kg})$ midlactation cow producing $45 \mathrm{~kg}$ milk/d to ensure consumption of 41.8 Mcal NE $/$ d (NRC, 2001).

Single-step analyses were carried out in the current study, such that adjustments for explanatory variables were made as genetic parameters for RFI were being calculated. The same approach was used by Ngwerume and Mao (1992), who also had small cohorts and re- 
Table 2. Phenotypic means \pm SD for all records $(\mathrm{n}=677)$ and primiparous $(\mathrm{n}=246)$ and multiparous $(\mathrm{n}=$ 431) cows (with minimum and maximum values in parentheses)

\begin{tabular}{lccc}
\hline Item & All records & Primiparous & Multiparous \\
\hline BW change (kg/d) & $0.37 \pm 0.39$ & $0.43 \pm 0.34$ & $0.33 \pm 0.42$ \\
& & $(-0.84,1.9)$ & $(-1.16,1.89)$ \\
BW $(\mathrm{kg})$ & $656 \pm 82$ & $595 \pm 54$ & $691 \pm 73$ \\
& & $(473,780)$ & $(480,963)$ \\
DMI $(\mathrm{kg})$ & $25.6 \pm 4.0$ & $22.6 \pm 2.9$ & $27.3 \pm 3.5$ \\
& & $(15.2,32.5)$ & $(17.1,42.6)$ \\
Milk energy (Mcal/d) & $28.3 \pm 5.5$ & $24.3 \pm 3.4$ & $30.5 \pm 5.2$ \\
& & $(13.2,33.6)$ & $(11.9,44.6)$ \\
Energy in BW change (Mcal/d) & $1.9 \pm 2.0$ & $2.2 \pm 1.8$ & $1.7 \pm 2.2$ \\
& & $(-4.1,11.0)$ & $(-5.6,10.0)$ \\
Energy for maintenance (Mcal/d) & $10.4 \pm 1.0$ & $9.6 \pm 0.7$ & $10.8 \pm 0.9$ \\
& & $(8.1,11.8)$ & $(8.2,13.8)$ \\
Energy intake (Mcal/d) & $40.5 \pm 5.8$ & $35.9 \pm 4.1$ & $43.16 \pm 4.89$ \\
& & $(24.7,48.1)$ & $(26.7,61.5)$ \\
Energy output ${ }^{1}$ (Mcal/d) & $40.5 \pm 5.8$ & $36.1 \pm 3.8$ & $43.0 \pm 5.2$ \\
Energy density (Mcal/kg of DM) & & $(24.2,50.0)$ & $(26.9,60.0)$ \\
& & $1.59 \pm 0.09$ & $1.58 \pm 0.09$ \\
DIM $^{2}$ & $1.58 \pm 0.09$ & $(1.41,1.75)$ & $(1.37,1.75)$ \\
& & $152 \pm 45$ & $148 \pm 46$ \\
& & $(81,274)$ & $(67,297)$ \\
\hline
\end{tabular}

${ }^{1}$ Output is the sum of the energy in milk, BW change, and maintenance.

${ }^{2}$ Days in milk at the midpoint of the record.

cords from multiple lactations. Conversely, Veerkamp et al. (1995), Vallimont et al. (2011), and Connor et al. (2013) carried out 2-step analyses; the first step involved regression of feed intake on its component traits, using larger cohorts defined by fixed effect such as diet, lactation, or herd, and in the second step residuals from this regression model were used as the phenotypes in a genetic analysis. The 2-step approach to calculating RFI is common in beef cattle, where a fixed effects model is used to compute RFI phenotypes and the these adjusted phenotypes are subsequently used as the dependent variable in an animal model analysis (Arthur et al., 2001a,b; Nkrumah et al., 2007).

\section{Heritability Estimates}

Heritability estimates for RFI and its component traits, on a weight $(\mathrm{kg})$ or energy (MCal) basis, are summarized in Table 3. Estimates for DMI as kilograms per day (0.27) and $\mathrm{NE}_{\mathrm{L}}$ in as megaclories per day (0.29) were similar. Our estimates were smaller than those summarized by Veerkamp (1998), in which the heritability of DMI $(\mathrm{kg})$ ranged from $(0.36-0.45)$ for studies in which primiparous and multiparous cows were fed a TMR ad libitum. However, our estimates were close to those reported by Spurlock et al. (2012) for the fourth and fifth months of lactation (0.29 and 0.22 , respectively), which align roughly with the time frame of the current study. The heritability estimate for MILKE as MCal/d (0.32) was less than that of lactation energy in Veerkamp et al. (1995), who reported an estimate of 0.45 , but greater than that of Spurlock et al. (2012), who reported estimates of 0.26 and 0.17 in the fourth and fifth months of lactation, respectively. The heritability estimates for MAINE as MCal/d (0.47) and BWCE (0.11) were within in the ranges $(0.32-0.61)$

Table 3. Estimates of heritability $\left(h^{2}\right)$, repeatability, additive genetic variance $\left(\sigma_{a}^{2}\right)$, permanent environmental variance $\left(\sigma_{p e}^{2}\right)$, and residual variance $\left(\sigma_{e}^{2}\right)$ for measures of residual feed intake (RFI) and its component traits: DMI, energy intake $\left(\mathrm{NE}_{\mathrm{L}}\right.$ in), milk energy (MILKE), energy in BW change (BWCE), and energy for maintenance (MAINE)

\begin{tabular}{lccccc}
\hline Item & \multicolumn{1}{c}{$\mathrm{h}^{2}$} & Repeatability & $\sigma_{a}^{2}$ & $\sigma_{p e}^{2}$ & $\sigma_{e}^{2}$ \\
\hline $\mathrm{RFI}_{\mathrm{kg}}$ & $0.04(0.09)$ & $0.14(0.12)$ & 0.13 & 0.30 & 2.69 \\
$\mathrm{RFI}_{\text {Mcal }}$ & $0.04(0.09)$ & $0.13(0.12)$ & 0.26 & 0.67 & 6.47 \\
DMI (kg/d) & $0.27(0.12)$ & $0.51(0.09)$ & 1.72 & 1.54 & 3.20 \\
NE $_{\mathrm{L} \text { in }(\mathrm{Mcal} / \mathrm{d})}$ & $0.29(0.12)$ & $0.50(0.09)$ & 4.53 & 3.37 & 7.76 \\
MILKE (Mcal/d) & $0.32(0.12)$ & $0.50(0.09)$ & 4.68 & 2.56 & 7.23 \\
BWCE (Mcal/d) & $0.11(0.09)$ & $0.15(0.11)$ & 0.36 & 0.15 & 2.56 \\
MAINE (Mcal/d) & $0.48(0.12)$ & $0.66(0.07)$ & 0.16 & 0.06 & 0.12 \\
\hline
\end{tabular}



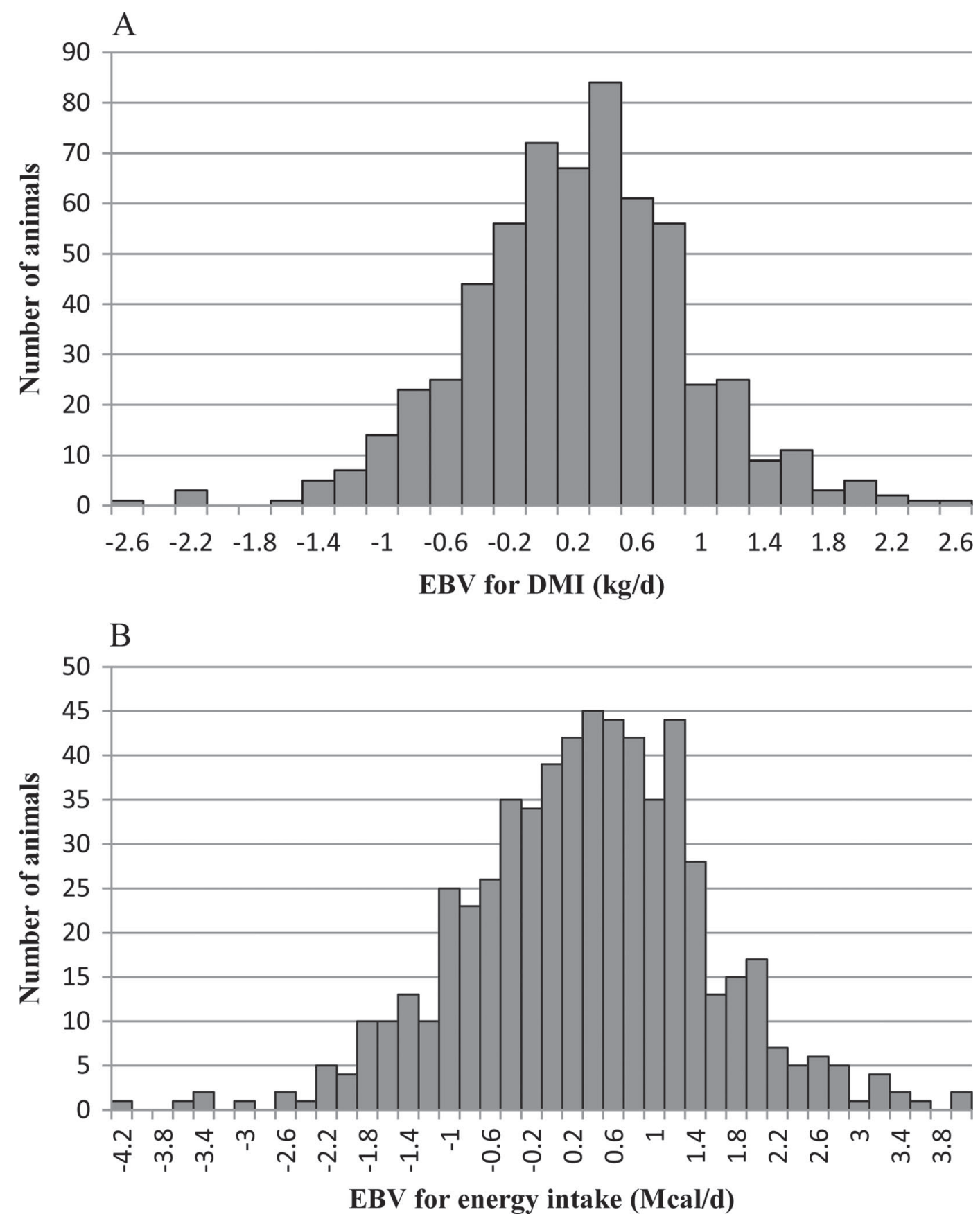

Figure 2. Estimated breeding values for the average daily intake measured as DMI (A) and megacalories of energy (B) for each of the 600 cows.

and (0.03-0.34) summarized by Berry et al. (2002) for $\mathrm{BW}$ and BWC, respectively. However, in the present study, the conversion from BWC as kilograms per day to BWCE as megacalories per day was a function of BCS, when available.

The estimated heritability for $\mathrm{RFI}_{\mathrm{Mcal}}$, in which $\mathrm{NE}_{\mathrm{L}}$ in $(\mathrm{MCal} / \mathrm{d})$ was regressed on MILKE, BWCE, and MAINE, was 0.035, whereas the estimated heri- tability for $\mathrm{RFI}_{\mathrm{kg}}$, in which DMI $(\mathrm{kg} / \mathrm{d})$ was regressed on MILKE, BWCE, and MAINE, was 0.041. These estimates were similar to heritability estimates for RFI (0.016-0.11) reported by Ngwerume and Mao (1992) in Holstein cows that were fed a TMR ad libitum, as well as estimates reported by Svendsen et al. (1993) for Norwegian Red cows and estimates reported by Lopez-Villalobos et al. (2008) for pasture-based Irish 


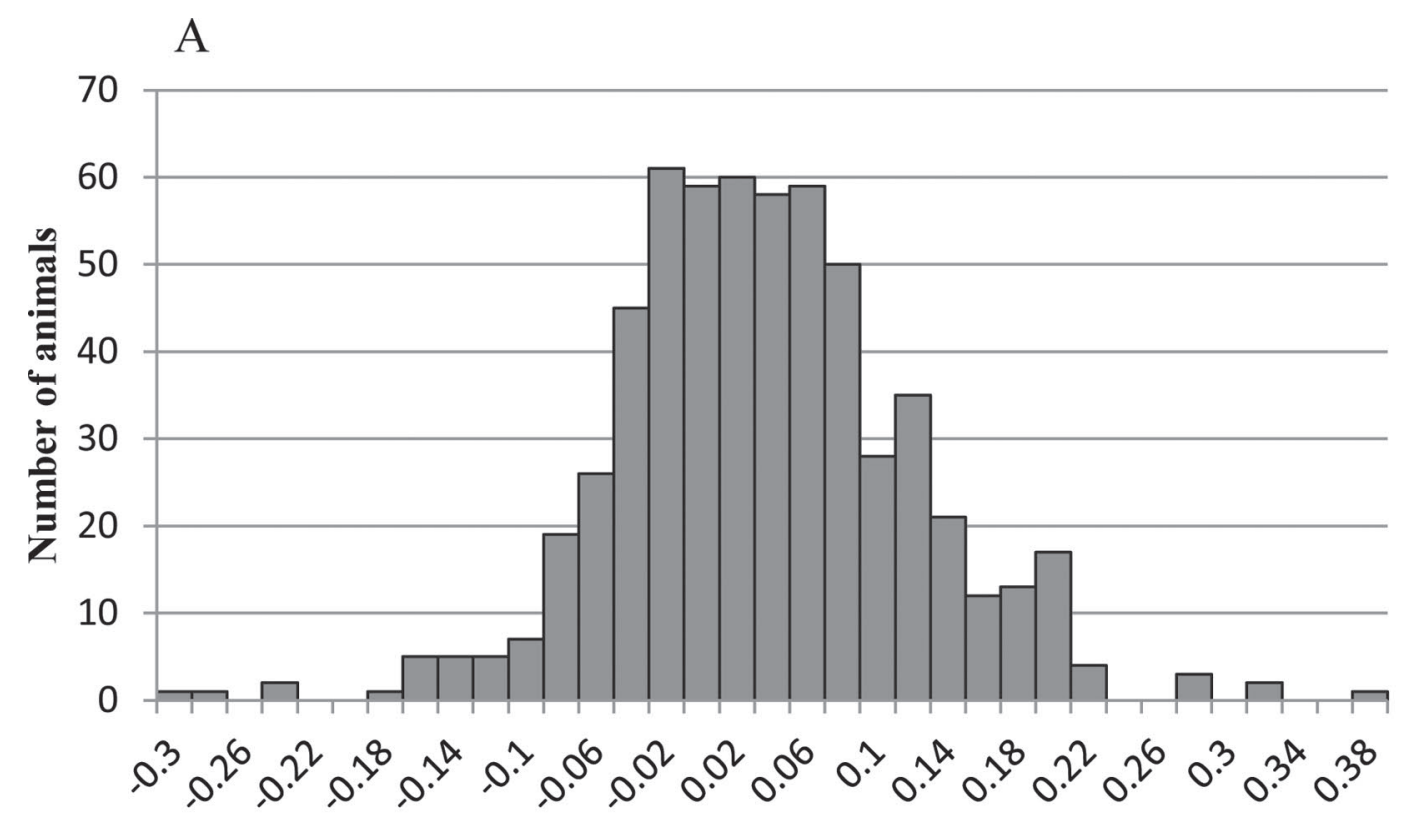

EBV for residual feed intake $(\mathrm{kg} / \mathrm{d})$

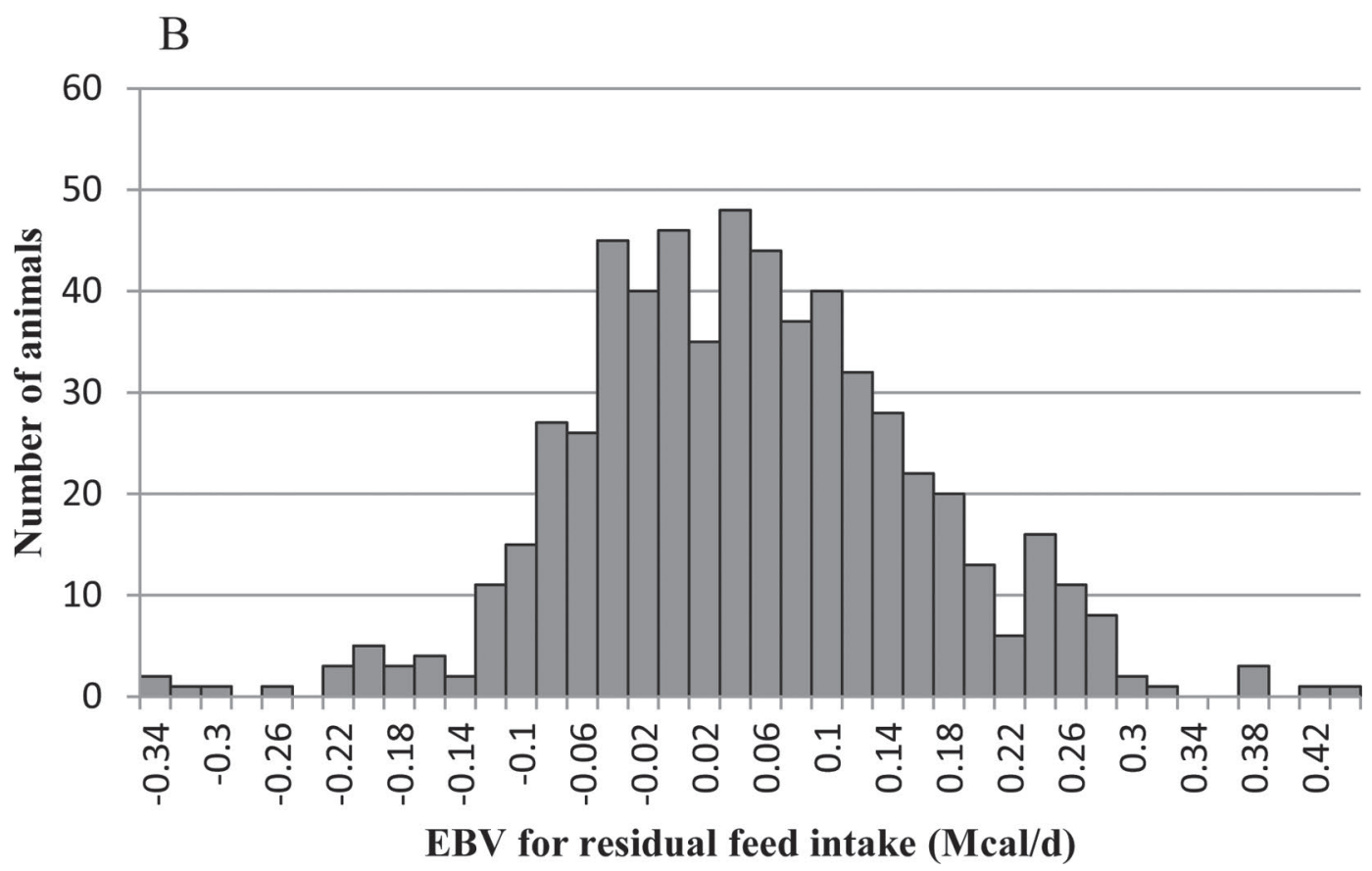

Figure 3. Estimated breeding values for residual feed intake (RFI) with intake measured as DMI (A) and megacalories of energy (B) for each of the 600 cows.

Holstein cows. However, Van Arendonk et al. (1991) and Veerkamp et al. (1995) reported higher heritability estimates of 0.19 for Dutch Holstein cows and 0.30 to 0.38 for Scottish Holstein-Friesian cows, respectively. Connor et al. (2013) reported the highest heritability estimates, ranging from 0.42 to 0.45 for Holstein cows at 53 to 102 DIM. As shown in Table 3, the heritability for RFI did not differ whether intake was entered in the model as DMI or megacalories of energy. However, all of these trials occurred in the Midwest and were performed by a few researchers. It is possible that by using data from more distinct climates with a wider variety 
Table 4. Genetic (above the diagonal) and phenotypic (below the diagonal) correlations between the component traits of residual feed intake (RFI), including DMI, energy intake $\left(\mathrm{NE}_{\mathrm{L}}\right.$ in), milk energy (MILKE), BW change (BWCE), and maintenance (MAINE)

\begin{tabular}{lccccc}
\hline Item $^{1}$ & $\begin{array}{c}\text { DMI } \\
(\mathrm{kg} / \mathrm{d})\end{array}$ & $\begin{array}{c}\mathrm{NE}_{\mathrm{L}} \text { in } \\
(\mathrm{Mcal} / \mathrm{d})\end{array}$ & $\begin{array}{c}\text { MILKE } \\
(\mathrm{Mcal} / \mathrm{d})\end{array}$ & $\begin{array}{c}\text { BWCE } \\
(\mathrm{Mcal} / \mathrm{d})\end{array}$ & $\begin{array}{c}\text { MAINE } \\
(\mathrm{Mcal} / \mathrm{d})\end{array}$ \\
\hline DMI (kg/d) & - & - & $0.86(0.12)$ & $0.45(0.43)$ & $0.44(0.22)$ \\
$\mathrm{NE}_{\mathrm{L}}$ in (Mcal/d) & - & $0.86(0.11)$ & $0.48(0.41)$ & $0.47(0.21)$ \\
MILKE (Mcal/d) & $0.63(0.03)$ & $0.64(0.03)$ & & - & $0.16(0.23)$ \\
BWCE (Mcal/d) & $0.14(0.04)$ & $0.14(0.04)$ & $-0.14(0.04)$ & & $0.68(0.26)$ \\
MAINE (Mcal/d) & $0.38(0.04)$ & $0.38(0.04)$ & $0.11(0.04)$ & $0.23(0.04)$ & \\
\hline
\end{tabular}

${ }^{1}$ The genetic correlations between DMI and $\mathrm{NE}_{\mathrm{L}}$ in, along with the genetic correlation between MILKE and BWCE, could not be estimated due to convergence problems.

of feedstuffs, it may be more critical to convert the diets to an energy basis. The EBV for DMI are shown in Figure 2, where the ranges in EBV are approximately 5.2 $\mathrm{kg} / \mathrm{d}$ and $8.0 \mathrm{MCal} / \mathrm{d}$, respectively. Likewise, the $\mathrm{EBV}$ for RFI are shown Figure 3, where the ranges in EBV are roughly $0.68 \mathrm{~kg} / \mathrm{d}$ and $0.76 \mathrm{MCal} / \mathrm{d}$, respectively.

\section{Phenotypic and Genetic Correlations}

Table 4 shows estimated phenotypic and genetic correlations between DMI $(\mathrm{kg} / \mathrm{d})$ and $\mathrm{NE}_{\mathrm{L}}$ in $(\mathrm{MCal} / \mathrm{d})$ and their component traits of MILKE, BWCE, and MAINE. Unsurprisingly, phenotypic correlations of DMI and $\mathrm{NE}_{\mathrm{L}}$ in with MILKE were strong and positive, at 0.63 and 0.64 , respectively. However, phenotypic correlations between the intake traits and BWCE and MAINE were only 0.14 and 0.38 , respectively. Genetic correlations of DMI and $\mathrm{NE}_{\mathrm{L}}$ in with MILKE were very high (0.86), indicating that increased milk production is strongly associated with increased intake. Genetic correlations of DMI and $\mathrm{NE}_{\mathrm{L}}$ in with MAINE were 0.44 and 0.47 , respectively. These estimates agree with the moderate to high genetic correlations between DMI and BW (0.23 to 0.86) summarized in Veerkamp (1998). However, Veerkamp (1998) reported negative genetic correlations between BWC and DMI $(-0.45$ to -0.23$)$, which contradict estimates from the present study in which genetic correlations of $\mathrm{DMI}$ and $\mathrm{NE}_{\mathrm{L}}$ in with BWCE were 0.45 and 0.48 , respectively. In the present study, larger cows tended to gain more weight and higher-producing cows tended to lose more weight. This could be due to the fact that many of the smaller primiparous cows were still growing, and therefore they did not demonstrate a large negative BWC. Additionally, the larger, higher-producing multiparous cows likely lost more BCS due to their greater demand for MILKE. Genetic correlations between the measures of RFI and the component traits could not be estimated because of convergence issues. This is likely because of the component trait being part of the phenotype for RFI.
Figure 4 shows a distribution of the $\mathrm{NE}_{\mathrm{L}}$ values as calculated using our method of dividing the sum of all energy expenditures within a cohort by the total DMI of the cohort. Figure 5 compares our realized energy densities with predicted energy densities based on nutrient analyses of 14 diets for which energy densities were represented in the original publications from their respective experiments (Table 1 ). Our realized densities tend to be slightly lower than those predicted based on the NRC (2001) equations. One possible reason for this discrepancy is that high DMI may increase the rate of passage of feed through the digestive tract, thereby reduce the cow's ability to digest and use the available nutrients, as compared with predictions based on the diet composition. Another possible explanation is that, if optimal rumen fermentation is not achieved (e.g., due to insufficient levels of fiber), the predicted energy values may be overestimated (NRC, 2001). Another possibility is that our model may not have properly accounted for all energy expenditures. For example, diets 13 and 14 (Figure 5) came from a study in which intakes were measured late in lactation, beyond the 100 d of gestation during which energy requirements for

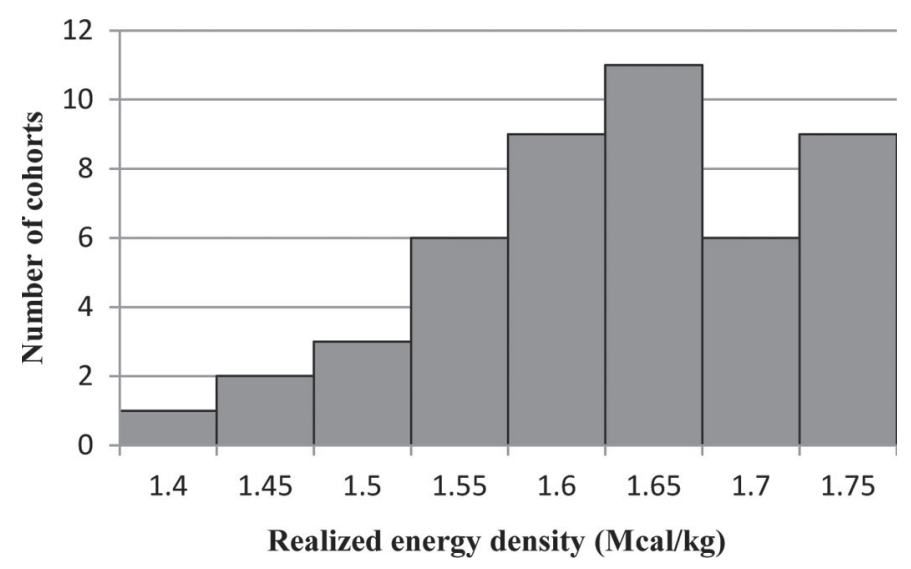

Figure 4. Distribution of calculated diet energy densities for each of the 46 cohorts from the 13 nutrition studies. 


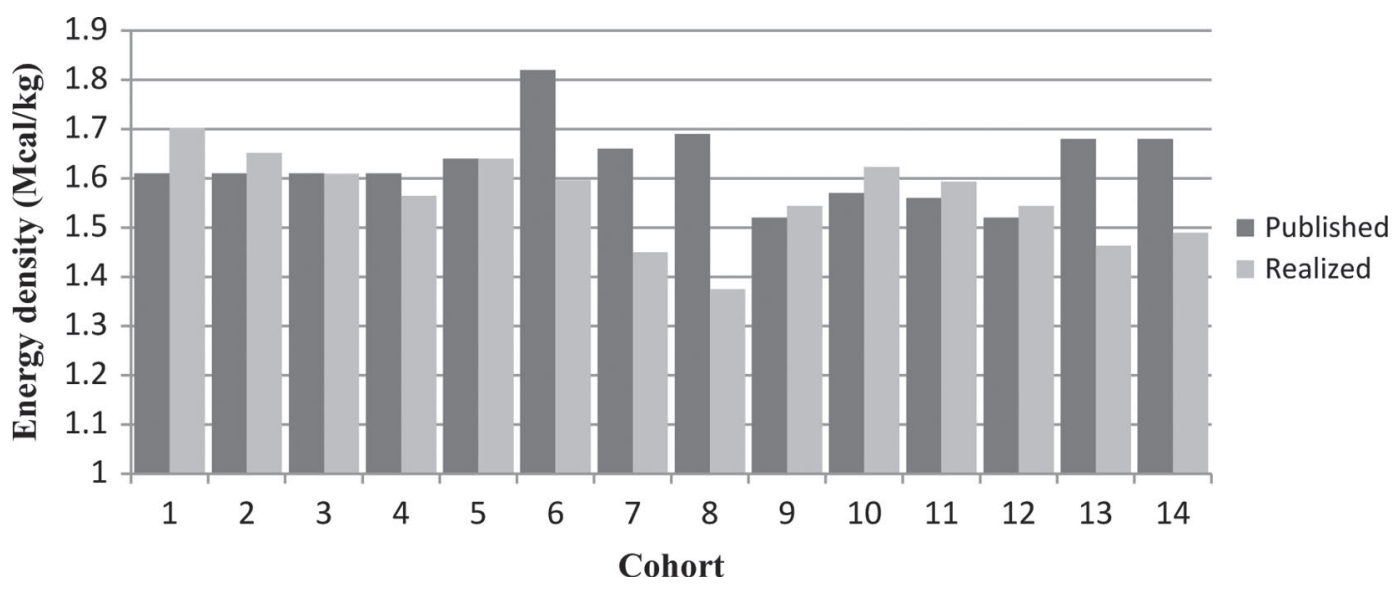

Figure 5. Predicted and calculated energy density of the diets for selected nutrition studies. The dark bars are values as predicted based on chemical analysis of the feed. The light bars are the energy density of the diets as calculated by our proposed method of summing the daily energy expended within cohort and dividing it by the cohort's total daily DMI. Cohorts $1-5, \mathrm{n}=10,10,9,9,9$, respectively (Chen et al., 2011); cohorts $6-8, \mathrm{n}=15,15,15$, respectively (Ferraretto et al., 2011); cohorts 9-12, $\mathrm{n}=15,16,13,14$, respectively (Ferraretto et al., 2012); and cohorts 13 and $14, \mathrm{n}=25,24$, respectively (He et al., 2012).

pregnancy are considered as negligible (NRC 2001). In addition, energy required for physical activity was not considered, as noted earlier, but one would expect this requirement to be very small in a freestall or tiestall setting. Lastly, energy requirements could have been affected slightly by climatic conditions, such as heat stress during the summer or extreme cold during the winter, and these requirements were not considered in the present study.

Deciding which studies to use in the end is no easy task. The value of adding a study needs to be weighed against the challenges it brings related to how different the study is from the majority of the others. If diet is largely the differing factor, we believe that expressing the intake as net energy, as we have done in this study, will be a suitable adjustment. Alternatively, if the studies separate themselves into logical subgroups, the feed efficiency measure could be considered as 2 different traits and analyzed with a multiple-trait model in which the genetic correlation between the groups is permitted to be less than one (Schaeffer, 1994). This would avoid the need to make adjustments within each subgroup, such as expressing the intake measurements as breeding values, before analyzing them together.

\section{CONCLUSIONS}

Intake phenotypes from nutrition studies can be used for estimating genetic parameters related to feed efficiency, and dividing total energy expended within a cohort by total energy intake of the cohort can provide reasonable estimates of the mean energy densities of the diets without carrying out extensive feed analyses. Information about realized energy density could be useful in standardizing intake data from different climate conditions or management systems, as well as investigating potential genotype by diet interactions. Additional research with more animals is needed to validate the genetic correlations between RFI and other traits and to quantify their expected correlated responses under selection for improved RFI.

\section{ACKNOWLEDGMENTS}

Support for this student training project was provided by USDA National Needs Graduate Fellowship Competitive Grant no. 2010-38420-20477 from the National Institute of Food and Agriculture (Washington, DC). Additionally, this project was supported by Agriculture and Food Research Initiative Competitive Grant no. 2011-68004-30340 from the USDA National Institute of Food and Agriculture. K. Weigel acknowledges financial support from the National Association of Animal Breeders (Columbia, MO).

\section{REFERENCES}

Akins, M. S., S. J. Bertics, M. T. Socha, and R. D. Shaver. 2013. Effects of cobalt supplementation and vitamin B12 injections on lactation performance and metabolism of Holstein dairy cows. J. Dairy Sci. 96:1755-1768.

Arthur, P. F., J. A. Archer, D. J. Johnston, R. M. Herd, E. C. Richardson, and P. F. Parnell. 2001b. Genetic and phenotypic variance and covariance components for feed intake, feed efficiency, and other postweaning traits in Angus cattle. J. Anim. Sci. 79:28052811.

Arthur, P. F., G. Renand, and D. Krauss. 2001a. Genetic and phenotypic relationships among different measures of growth and feed efficiency in young Charloais bulls. Livest. Prod. Sci. 68:131-139.

Banos, G., M. P. Coffey, R. F. Veerkamp, D. P. Berry, and E. Wall. 2012. Merging and characterising phenotypic data on conventional 
and rare traits from dairy cattle experimental resources in three countries. Animal 6:1040-1048.

Berry, D. P., F. Buckley, P. Dillon, F. D. Evans, M. Rath, and R. F. Veerkamp. 2002. Genetic parameters for level and change of body condition score and body weight in dairy cows. J. Dairy Sci. 85:2030-2039.

Buttazzoni, L., and I. L. Mao. 1989. Genetic parameters of estimated net energy efficiencies for milk production, maintenance, and body weight change in dairy cows. J. Dairy Sci. 72:671-677.

Chapinal, N., D. M. Veira, D. M. Weary, and M. A. G. von Keyserlingk. 2007. Technical note: Validation of a system for monitoring individual feeding and drinking behavior and intake in grouphoused cattle. J. Dairy Sci. 90:5732-5736.

Chen, Z. H., G. A. Broderick, N. D. Luchini, B. K. Sloan, and E. Devillard. 2011. Effect of feeding different sources of rumen-protected methionine on milk production and N-utilization in lactating dairy cows. J. Dairy Sci. 94:1978-1988.

Connor, E. E., J. L. Hutchison, K. M. Olson, and H. D. Norman. 2012. Triennial lactation symposium: Opportunities for improving milk production efficiency in dairy cattle. J. Anim. Sci. 90:1687-1694.

Connor, E. E., J. L. Hutchison, H. D. Norman, K. M. Olson, C. P. Van Tassell, J. M. Leith, and R. L. Baldwin VI. 2013. Use of residual feed intake in Holsteins during early lactation shows potential to improve feed efficiency through genetic selection. J. Anim. Sci. 91:3978-3988.

de Haas, Y., M. P. L. Calus, R. F. Veerkamp, E. Wall, M. P. Coffey, H. D. Daetwyler, B. J. Hayes, and J. E. Pryce. 2012. Imporved accuracy of genomic prediction for dry matter intake of dairy cattle from combined European and Australian data sets. J. Dairy Sci. 95:6103-6112.

Edmonson, A. J., I. J. Lean, L. D. Weaver, T. Farver, and G. Webster. 1989. A body condition scoring chart for Holstein dairy cows. J. Dairy Sci. 72:68-78.

Fan, L. Q., D. R. Bailey, and N. H. Shannon. 1995. Genetic parameter estimation of postweaning gain, feed intake, and feed efficiency for Hereford and Angus bulls fed two different diets. J. Anim. Sci. $73: 365-372$

Ferraretto, L. F., R. D. Shaver, and S. J. Bertics. 2012. Effect of dietary supplementation with live-cell yeast at two dosages on lactation performance, ruminal fermentation, and total-tract nutrient digestibility in dairy cows. J. Dairy Sci. 95:4017-4028.

Ferraretto, L. F., R. D. Shaver, M. Espineira, H. Gencoglu, and S. J. Bertics. 2011. Influence of a reduced-starch diet with or without exogenous amylase on lactation performance by dairy cows. J. Dairy Sci. 94:1490-1499.

Gilmour, A. R., B. J. Gogel, B. R. Cullis, and R. Thompson. 2008. ASReml User guide. Release 3.0. VSN International Ltd., Hemel Hempstead, UK.

Hayes, B. J., P. J. Bowman, A. J. Chamberlain, and M. E. Goddard. 2009. Invited review: Genomic selection in dairy cattle: Progress and challenges. J. Dairy Sci. 92:433-443.

He, M., K. L. Perfield, H. B. Green, and L. E. Armentano. 2012. Effect of dietary fat blend enriched in oleic or linoleic acid and monensin supplementation on dairy cattle performance, milk fatty acid profiles, and milk fat depression. J. Dairy Sci. 95:1447-1461.

Kennedy, B. W., J. H. van der Werf, and T. H. Meuwissen. 1993. Genetic and statistical properties of residual feed intake. J. Anim. Sci. 71:3239-3250.
Koch, R. M., L. A. Swiger, D. Chambers, and K. E. Gregory. 1963. Efficiency of feed use in beef cattle. J. Anim. Sci. 22:486-494.

Korver, S. 1988. Genetic aspects of feed intake and feed efficiency in dairy cattle: A review. Livest. Prod. Sci. 20:1-13.

Korver, S., E. A. M. van Eekelen, H. Vos, G. J. Nieuwhof, and J. A. M. van Arendonk. 1991. Genetic parameters for feed intake and feed efficiency in growing dairy heifers. Livest. Prod. Sci. 29:49-59.

Lopez-Villalobos, N., D. P. Berry, B. Horan, F. Buckley, J. Kennedy, M. O'Donovan, L. Shalloo, and P. Dillon. 2008. Genetics of residual energy intake in Irish grazing dairy cows. Proc. N.Z. Soc. Anim. Prod. 68:88-91.

Meuwissen, T. H. E., B. J. Hayes, and M. E. Goddard. 2001. Prediction of total genetic value using genome-wide dense marker maps. Genetics 157:1819-1829.

NRC. 2001. Nutrient Requirements of Dairy Cattle. 7th rev. ed. Natl. Acad. Sci., Washington, DC.

Ngwerume, F., and I. L. Mao. 1992. Estimation of residual energy intake for lactating cows using an animal model. J. Dairy Sci. 75:2283-2287.

Nkrumah, J. D., D. H. Crews Jr., J. A. Basarab, M. A. Price, E. K. Okine, Z. Wang, C. Li, and S. S. Moore. 2007. Genetic and phenotypic relationships of feeding behavior and temperament with performance, feed efficiency, ultrasound, and carcass merit of beef cattle. J. Anim. Sci. 85:2382-2390.

Schaeffer, L. R. 1994. Multiple-country comparison of dairy sires. J. Dairy Sci. 77:2671-2678.

Spurlock, D. M., J. C. M. Dekkers, R. Fernando, D. A. Koltes, and A. Wolc. 2012. Genetic parameters for energy balance, feed efficiency, and related traits in Holstein cattle. J. Dairy Sci. 95:5393-5402.

Svendsen, M., P. Skipenes, and I. L. Mao. 1993. Genetic parameters in the feed conversion complex of primiparous cows in the first two trimesters. J. Anim. Sci. 71:1721-1729.

USDA-National Agricultural Statistics Service (NASS). 2013. Wisconsin 2013 Agricultural Statistics. Accessed Feb. 10, 2014. http:// www.nass.usda.gov/Statistics_by_State/Wisconsin/Publications/ Annual_Statistical_Bulletin/bulletin2013_web.pdf.

Vallimont, J. E., C. D. Dechow, J. M. Daubert, M. W. Dekleva, J. W. Blum, C. M. Barlieb, W. Liu, G. A. Varga, A. J. Heinrichs, and C. R. Baumrucker. 2010. Genetic parameters of feed intake, production, body weight, body condition score, and selected type traits of Holstein cows in commercial tiestall barns. J. Dairy Sci. 93:4892-4901.

Vallimont, J. E., C. D. Dechow, J. M. Daubert, M. W. Dekleva, J. W. Blum, C. M. Barlieb, W. Liu, G. A. Varga, A. J. Heinrichs, and C. R. Baumrucker. 2011. Short communication: Heritability of gross feed efficiency and associations with yield, intake, residual intake, body weight, and body condition score in 11 commercial Pennsylvania tie stalls. J. Dairy Sci. 94:2108-2113.

Van Arendonk, J. A. M., G. J. Nieuwhof, H. Vos, and S. Korver. 1991 Genetic aspects of feed intake and efficiency in lactating dairy heifers. Livest. Prod. Sci. 29:263-275.

Veerkamp, R. F. 1998. Selection for economic efficiency of dairy cattle using information on live weight and feed intake: a review. J. Dairy Sci. 81:1109-1119.

Veerkamp, R. F., G. C. Emmans, A. R. Cromie, and G. Simm. 1995. Variance components for residual feed intake in dairy cows. Livest. Prod. Sci. 41:111-120. 